\title{
Phosphorylation meets nuclear import: a review
}

\author{
Jonathan D Nardozzi ${ }^{1}$, Kaylen Lott ${ }^{1,2}$, Gino Cingolani ${ }^{2 *}$
}

\begin{abstract}
Phosphorylation is the most common and pleiotropic modification in biology, which plays a vital role in regulating and finely tuning a multitude of biological pathways. Transport across the nuclear envelope is also an essential cellular function and is intimately linked to many degeneration processes that lead to disease. It is therefore not surprising that phosphorylation of cargos trafficking between the cytoplasm and nucleus is emerging as an important step to regulate nuclear availability, which directly affects gene expression, cell growth and proliferation. However, the literature on phosphorylation of nucleocytoplasmic trafficking cargos is often confusing. Phosphorylation, and its mirror process dephosphorylation, has been shown to have opposite and often contradictory effects on the ability of cargos to be transported across the nuclear envelope. Without a clear connection between attachment of a phosphate moiety and biological response, it is difficult to fully understand and predict how phosphorylation regulates nucleocytoplasmic trafficking. In this review, we will recapitulate clue findings in the field and provide some general rules on how reversible phosphorylation can affect the nuclear-cytoplasmic localization of substrates. This is only now beginning to emerge as a key regulatory step in biology.
\end{abstract}

\section{Introduction}

\section{Principles of Nucleocytoplasmic Transport}

The nucleus is the key organelle where most of the cellular genetic information is stored. Transcription is also compartmentalized to the nucleus to keep it separate from translation, which occurs in the cytoplasm. The nucleus is separated from the cytoplasm by a double lipid bilayer known as the nuclear envelope (NE), which is composed of an outer and an inner nuclear membrane (abbreviated as ONM and INM). At distinct points, the ONM and INM are conjoined by large macromolecular assemblies known as nuclear pore complexes (NPCs). Because of this peculiar morphology, all transport across the nuclear envelope is physically restricted to occur through the NPC. The NPC is not simply a channel, but mediates the exchange of macromolecules into and out of the nucleus imposing selectivity like a semi-permeable filter [1]. Accordingly, proteins smaller than $\sim 40 \mathrm{kDa}$ can usually diffuse through the NPC, while larger proteins are shuttled through the NPC by dedicated nuclear transport receptors of the $\beta$-karyopherin family, which includes at least 20 different known importins and exportins in humans [2]. Much is

\footnotetext{
* Correspondence: gino.cingolani@jefferson.edu

${ }^{2}$ Dept. of Biochemistry and Molecular Biology, Thomas Jefferson University,

233 South 10th Street, Philadelphia, PA 19107, USA

Full list of author information is available at the end of the article
}

known about the molecular basis for the recognition of import/export cargos by $\beta$-karyopherins. As a general rule, substrates moving through the NPC typically expose molecular flags on their surface, thereby promoting efficient recognition and binding by karyopherins. Import cargos posses a Nuclear Localization Signal (NLS) that can be recognized by a karyopherin directly or in the presence of an adaptor protein (reviewed in [3-7]). Typically, NLSs are highly enriched in basic residues (e.g. Lysine, Arginine). Well-studied examples of classical NLSs are those of the SV40-Large T antigen [6], and the bipartite NLS of nucleoplasmin, which contains two basic clusters spaced by $\sim 10$ less conserved residues (Figure 1A). In contrast, cargos traveling toward the cytoplasm usually display a leucine-rich Nuclear Export Signal (NES), which contains critical hydrophobic residues, necessary for recognition by the nuclear export receptor Crm1[8].

$\beta$-karyopherins were originally identified based on their ability to bind the small GTPase Ran through an N-terminal binding domain [9]. Ran, a small GTPase of the Rassuperfamily, is recognized as the main source of both the energy and directionality of nucleocytoplasmic transport $[10,11]$. This GTPase exists in different nucleotide-bound states across the nuclear envelope. The nuclear population of Ran is predominately GTP-bound, whereas the cytoplasmic pool of Ran is GDP-bound due to the sequestering of its RanGEF (named RCC1) and RanGAP 


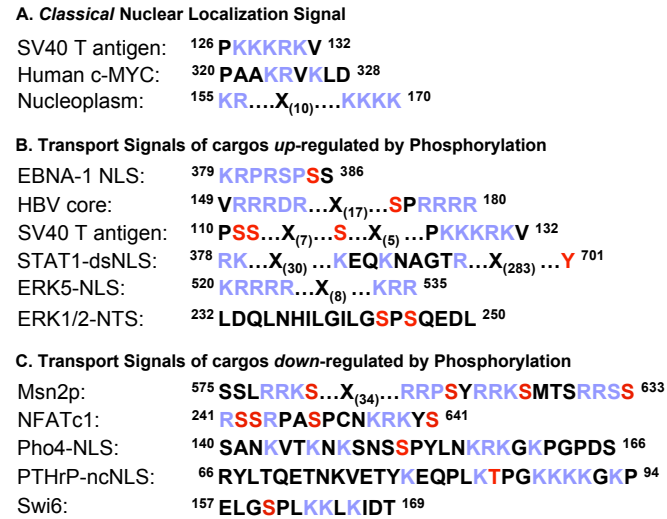

Figure 1 Amino acid sequence of several known nuclear targeting sequences. (A) Classical Nuclear Localization Signals. Nuclear import signals of cargos (B) up-regulated and (C) downregulated by phosphorylation. Colored in blue are basic amino acids within the import signal, usually critical for recognition by karyopherins. In red are sites of phosphorylation that have been shown to modulate nuclear import.

to the nucleus and cytoplasm, respectively $[12,13]$. The high concentration of Ran-GTP found in the nucleus is needed to dissociate incoming import complexes, and also to assemble outgoing export complexes.

The most widely characterized $\beta$-karyopherin family member, importin $\beta 1$ (reviewed in $[2,14]$ ) imports substrates directly or in complex with the adaptor proteins such as importin $\alpha$ or snurportin [15]. In the 'classical' nuclear import pathway [3-7], the adaptor importin $\alpha 1$ recognizes and binds a cytoplasmic cargo bearing a classical NLS. Importin $\alpha 1$ is tethered to importin $\beta 1$ via its $N$-terminal importin $\beta$ binding (IBB) domain [16] and the ternary complex of importin 1 /importin 1 /NLS is shuttled through the nuclear pore complex. Upon binding to RanGTP, the import complex falls apart, thereby releasing the import cargo in the cell nucleus, and importin $\beta 1$ is shuttled back to the cytoplasm. In addition to importin $\alpha 1$, which recognizes classical NLSs, humans posses five additional isoforms of importin $\alpha$, which fall into three distinct phylogenetic groups, namely the $\alpha 1 \mathrm{~s}, \alpha 2 \mathrm{~s}$ and $\alpha 3 \mathrm{~s}[17,18]$ (Figure 2A). The functional diversification of importin $\alpha$ s occurred throughout evolution along with the evolution of multicellular animals. This reflects the increasingly complex and regulated nature of higher organisms and the need to perform cell and tissue specific functions during development and differentiation [17]. Whereas different importin $\alpha$ paralogs share the ability to bind and import classical NLS substrates only certain animal isoforms can recognize specific non-classical cargos. For instance, importin $\alpha 5$ (also known as NPI-1 is involved in the nuclear import of dimeric phosphorylated STAT1 [19] and influenza virus polymerase PB2 (Figure 2B) [20], while importin $\alpha 3$ (Qip-1) mediates translocation of $\mathrm{NF}-\kappa \mathrm{B}$ p50/p65 heterodimer into the nucleus [21].

In addition to the prototypical receptor importin $\beta 1$, other $\beta$-karyopherins are well characterized. For instance, importin $\beta 2$ (also known as transportin) mediates nuclear import of cargos containing an M9-signal [22]; or Crm1 recognizes NES-containing cargos in the presence of RanGTP and is responsible for their export out of the nucleus [3-7]. Overall, import and export complexes moving between the cytoplasm and nucleoplasm travel approximately $200 \mathrm{~nm}$ through the NPC to complete a round of translocation. This is a dynamic process that requires extensive interactions of $\beta$-karyopherins with the NPC.

\section{The Nuclear Pore Complex}

It is impossible to appreciate the complexity of nucleocytoplasmic trafficking without acknowledging the morphology and composition of the NPC. In vertebrates, the NPC is a $125 \mathrm{MDa}$ macromolecular assembly composed of approximately thirty proteins, termed nucleoporins (nups) (reviewed in [23-26]). The nups are arranged into an octagonal symmetric pore that contains a central channel, sandwiched between a cytoplasmic and a nucleoplasmic ring of nucleoporins. These rings extend eight filaments deep into their respective cellular compartments. The cytoplasmic filaments, composed mainly of Nup358, extend flexibly into the cytoplasm and contain four RanBP1-like domains [27]. SUMO1 targets the Ran GTPase-activating protein RanGAP1 to Nup358, and together, these two proteins play a critical role in maintaining the Ran gradient across the nuclear envelope [13]. In contrast, the ends of the nucleoplasmic filaments, composed mainly of Nup153, are joined in a distal ring called the nuclear basket, which functions to arrest nuclear transport receptors awaiting cargo release in the nucleus [28]. About one third of nucleoporins in the NPC is highly enriched in phenylalanine-glycine repeats (FG-nups). These FG-nups are highly unstructured and are thought to be responsible for gating the NPC [29]. Increasing evidence indicates that the soluble FG-nups adopt a natively unfolded conformation [30] that may 'fill' the NPC inner channel and make it impermeable to cargos larger than $\sim 40 \mathrm{kDa}$. Several models for translocation through the NPC have been proposed [30-33], although the lack of a direct way to study the movement of protein through the NPC hinders an accurate and quantitative characterization of the translocation mechanisms.

\section{Phosphorylation in Nuclear Transport}

Reversible phosphorylation of amino acid side chains is the most widely characterized post-translational modification in biology (reviewed in [34-37]). Phosphorylation can either 


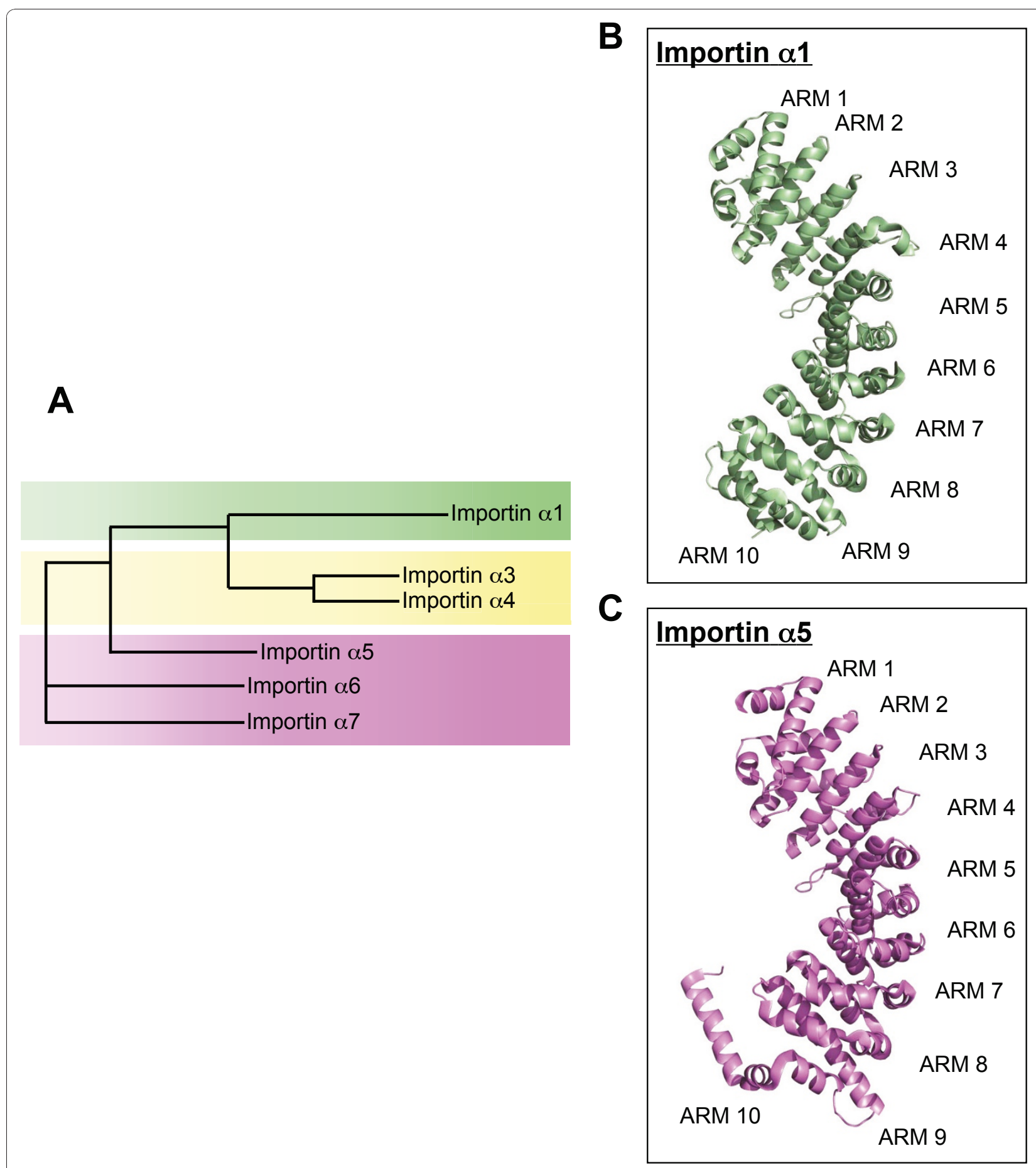

Figure 2 Diversification of the human nuclear import adaptor importin $\boldsymbol{\alpha}$. (A) A phylogenetic tree showing the evolutionary divergence of the six different human importin $\alpha$ isoforms. The branch lengths are proportional to the predicted evolutionary time between sequences. Three subfamilies of importin $\alpha$ (shaded in green, yellow and magenta) are identified. Both sequence alignment and phylogenetic tree were generated using the program ClustalW [164]. Ribbon diagram of the mammalian importin $\alpha 1$ (B) (pdb 1EJL) and importin $\alpha 5$ (C) (pdb 2JDQ) (in green and violet, respectively). Both structures consist of 10 tandemly repeated Armadillo repeats (ARM), each formed by three $\alpha$-helices. Significant differences can be seen between importin $\alpha 1$ and $\alpha 5$ C-terminal ARM-10, which is partially extended in $\alpha 5$ [20]. Both crystal structures in panel (B-C) lack the N-terminal Importin $\beta$ binding (IBB) domain, which promotes binding to the receptor importin $\beta$. 
activate or inactivate biological pathways and is commonly used to switch enzyme activity "on" or "off". The enzymes responsible for addition and removal of a phosphate moiety, kinases and phosphatases, respectively, are highly abundant in nature. Genomics studies have shown that the human genome contains 518 protein kinases and only 147 protein phosphatase catalytic subunits, of which 107 belong to the Tyrosine phosphatase family [38]. This gives rise to countless networks of phosphorylation/dephosphorylation events that control the most diverse biological pathways. This review will focus only on the regulatory role of phosphorylation in nuclear transport.

Phosphorylation can have either an enhancing or an inhibitory effect on nuclear import, and unfortunately the molecular consequences of phosphorylation have been elucidated in very few systems [7]. Understanding how phosphorylation affects nuclear import is a difficult task and likely many more cargos than those few characterized to date (discussed in this review) are regulated by phosphorylation. It is generally accepted that cargos smaller than $\sim 40$ $\mathrm{kDa}$ can slowly diffuse into the nucleus, while larger cargos are actively imported by karyopherins. However, some of the smallest proteins in a cell (e.g. Hiv-1 Rev [39], PTHrP [40], histone H1 [41], etc.) use karyopherin-mediated, signal-dependent import pathways, clearly demonstrating that nuclear import is about the rate at which cargos enter the cell nucleus, and not their size. Unfortunately, the two most common assays used to study nuclear transport, the nuclear import assay in digitonin permeabilized mammalian cells [42] and transfection, are both carried out at equilibrium. These assays do not measure rates of import, but just the resultant of import and export localization at steady-state. This makes it difficult, if not impossible, to dissect the role of phosphorylation in cases where the posttranslational modification does not completely stimulate or repress nuclear import. As often in biology, phosphorylation and other post-translational modification finely tune biochemical reactions by up- or downregulating basal levels of transport. Thus, a quantitative analysis of the role of phosphorylation on nuclear import is still in its infancy. In reviewing the literature on this topic, we have identified at least six ways by which phosphorylation can stimulate nuclear import. In contrast, there are only two characterized ways by which phosphorylation has been shown to down-regulate passage of cargos through the NPC. Both aspects of the phosphorylation-mediated regulation of nuclear transport will be discussed below.

\section{Up-Regulation of Nuclear Import by Phosphorylation}

Phosphorylation within an NLS enhances the binding affinity for the isoform importin $\alpha 5$

Perhaps the most intuitive way by which phosphorylation enhances nuclear import of a cargo is by increasing its affinity for a specific import factor. There are several well-documented examples of import cargos that fall under this category. One case is the Epstein-Barr virus (EBV) nuclear antigen 1 (EBNA-1) protein (Figure 3A), which is essential for the replication of EBV DNA in latently infected cells [43]. During infection EBNA-1 enters the nucleus of infected cells and functions as a transactivator of latent genome transcription [44]. It was shown that phosphorylation of $\mathrm{Ser}^{385}$ in the EBNA-1 NLS (Figure 1B) up-regulates its nuclear transport by increasing the binding affinity for the import adaptor importin $\alpha 5$ (Figure $2 \mathrm{C}$ ), which in turn recruits the receptor importin $\beta 1$ [45].

Interestingly, replacement of $\operatorname{Ser}^{385}$ with the phosphomimetic aspartic acid decreases the binding affinity for importin $\alpha 5$, demonstrating that the specificity of the response is dependent on the phosphate moiety. Additionally, biophysical studies using chemically synthesized peptides and isothermal titration calorimetry determined that phosphorylation of $\mathrm{Ser}^{385}$ in EBNA-NLS increases the binding affinity for importin $\alpha 5$ by $\sim 20$-fold, compared to the unphosphorylated NLS $\left(\mathrm{K}_{\mathrm{d}} \sim 3 \mu \mathrm{M}\right.$ versus $60 \mu \mathrm{M})$ [46]. Thus the phosphate moiety within EBNA1 NLS functions as a direct binding determinant for importin $\alpha 5$; phosphorylation of $\operatorname{Ser}^{385}$ within the NLS stimulates nuclear import by enhancing the binding affinity of EBNA-1 for the import adaptor importin $\alpha 5$.

\section{Phosphorylation enhances docking of cargos to the Nuclear Pore Complex}

The human Hepatitis B virus (HBV) undergoes an elegant and tightly regulated mechanism of entry into the host nucleus to replicate its genome. A mature HBV particle contains an envelope with surface glycoproteins that surrounds an icosohedral capsid (composed of 180 or 240 copies of the $21 \mathrm{kDa}$ core protein) containing the viral dsDNA genome, a viral polymerase and the host proteins Protein Kinase C (PKC) and hsp90 [47]. Progeny HBV particles assemble in the cytoplasm, but require the host RNA polymerase II in the nucleus for viral genome replication [48], making nuclear import of the genome a necessary step in viral replication. It was shown by Rabe et al. that the entire HBV core particle (32-36 nm diameter [49]) traverses the NPC in a phosphorylation-dependent manner [50]. The core protein displays an arginine-rich NLS at its C-terminus [51] (Figure 1B), which overlaps with a nucleic acid binding domain [52] and five serine phosphorylation sites [53]. The C-terminus of the core protein is buried inside the capsid [54] and interacts with the viral genome through the nucleic acid binding domain. The host PKC, also present in the infectious virion, phosphorylates the core protein at Ser ${ }^{172}$, thereby triggering a conformational change that exposes the core protein C-terminal NLS 


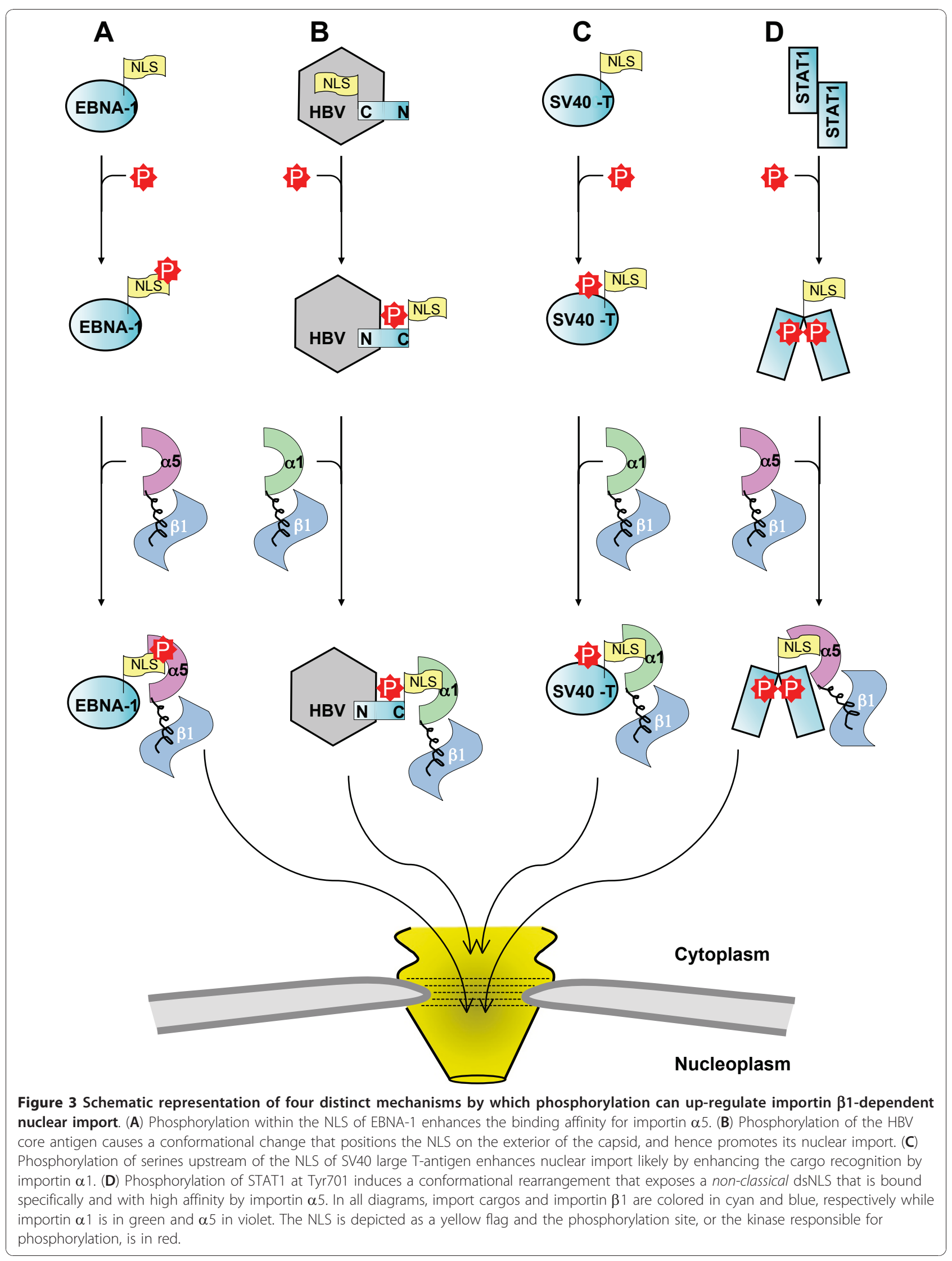


on the capsid surface (Figure 3B). Upon phosphorylation, the HBV core particle is recognized by an importin $\beta 1 /$ importin $\alpha 1$ heterodimer and imported into the nucleus in a Ran and energy-independent manner [47]. Nuclear transport of the HBV core particle arrests at the nuclear basket [55], the capsid disassembles, and the viral genome is released into the nucleus and transcribed by the host RNA polymerase II. Core protein phosphorylation is clearly the key step in the nuclear import of HBV particles, but it is tightly coupled to the maturity of the viral genome. The host RNA polymerase II transcribes a pregenomic RNA, which is exported from the nucleus and trapped within newly forming capsids. Within the capsid, pregenomic RNA is then reverse-transcribed, and an incomplete complementary DNA strand is created. The genome maturity is not only dependent on the aforementioned events, but also on phosphorylation of the capsid proteins, which are thought to stabilize the HBV genome [56]. It was shown that the exposure of the core protein C-terminal NLS is directly proportional to genome maturity, and while immature virions are arrested at the NPC, only replication-competent capsids are imported into the nucleus [50].

\section{Phosphorylation upstream the classical SV40 NLS enhances its recognition by importin $\alpha 1$}

The enhanced nuclear import of phosphorylated cargos does not always depend on direct interaction of the import machinery with the phosphate moiety. The first identified and likely one of the best-characterized NLSs is that of the large tumor antigen of simian-virus 40 (SV40) (Figure 1B). Upstream of the basic cluster, which spans residues 127-131, there are several phosphorylation sites (110-P $\underline{\underline{S}}{ }^{111} \underline{{ }^{112}}$ DDEAAAD $\underline{\underline{S}}{ }^{120} \mathrm{QHAAPPKKKRKVG-133)}$ (Figure 1B). It was reported that phosphorylation at $\mathrm{S}^{111 /}$ $\mathrm{S}^{112}$ by protein kinase CK2 accelerates the nuclear import of SV40 large T-antigen 50-fold [57,58] and phosphorylation at an additional site, $\mathrm{S}^{120}$, by the double-stranded DNA-dependent protein kinase, further enhances nuclear import [59]. However, a crystal structure of importin $\alpha 1$ (lacking the IBB domain) in complex with a phosphoNLS peptide spanning region 109-133 of the SV40 large $\mathrm{T}$-antigen showed that the phosphorylation sites do not make specific contacts with importin $\alpha 1$ (Figure 2B). Likewise, binding studies revealed that phosphorylation upstream of the SV40 T-antigen NLS does not increase the affinity of the NLS to importin $\alpha 1$ [60]. Interestingly, in the same crystal structure, it was observed that certain SV40 T-antigen residues upstream of the basic cluster also make specific contacts with importin $\alpha$ that are distinct from the binding sites of classical NLSs [61]. Based on these findings, it was proposed that phosphorylation upstream of the classical NLS might play a role in nuclear import by modulating the recognition of the NLS, rather than increasing the binding affinity of the NLS for importin $\alpha 1$ (Figure 3C). Furthermore, the observation that importin $\alpha 1$ does not bind the phosphate moiety directly further reinforces the idea that phosphorylation can play a regulatory role outside of the simple NLS-binding groove.

\section{Phosphorylation of STAT1 induces a conformational change that exposes a dimer-specific NLS}

STATs (Signal Transducers and Activators of Transcription) form an important family of transcription factors that play a critical role in cellular viability, immune response, and development. There are seven known human STAT isoforms that share a fundamentally conserved multi-domain architecture composed of an $\mathrm{N}$-terminal dimerization domain [62], a core consisting of a coiled-coil domain, DNA-binding domain, Src2 Homology domain (SH2) [63-65], and a C-terminal transactivation domain [66]. Each domain has critical roles in STAT activation, nuclear transport, or transcriptional activity. Consistent with their function of transcription factors, STATs have developed numerous ways to traverse the NPC and gain access to the nucleus; phosphorylation plays an essential role in this process.

The first STAT family member to be characterized, STAT1, mediates the innate immune response [67]. Upon stimulation of extracellular receptors, STAT1 is recruited to the cell surface and activated through tyrosine phosphorylation at position $\mathrm{Tyr}^{701}$ [68]. Phosphorylation of STAT1 induces homodimerization through a reciprocal SH2-phosphoTyr interaction with another STAT1 monomer [68]. This dimerization leads to a structural rearrangement [69] of STAT1 that exposes a dimer-specific NLS (dsNLS) in its DNA-binding domain (Figure 1B) [70-73]. The STAT1 dsNLS differs from a classical NLS (cNLS) in numerous ways. First, the dsNLS is not recognized by importin $\alpha 1$, but as in the case of EBNA-1 phosphoNLS, by the isoform importin $\alpha 5$ (Figure 3D) [74]. Second, STAT1 does not bind only the major and minor NLS binding grooves of importin $\alpha 5$, but requires importin $\alpha 5 \mathrm{C}$-terminal Armadillo repeats (ARM) 9 and 10 for high affinity binding [46]. The final and most unconventional characteristic of the dsNLS is that it only functions in the context of phosphorylated STAT1 [70]. Whereas classical NLSs can be removed from the context of the native protein and function in trans when attached to an exogenous protein, the STAT1 NLS is only functional in cis, within the context of the pSTAT1 tertiary structure. This was elegantly shown by Meyer et al. who studied a peptide spanning residues 376-427 of the STAT1 DNA-binding domain and found that it did not accumulate in the nucleus in a micro-injection nuclear import assay [70]. Because the STAT1 DNA binding domain is exposed in 
the active dimer of phosphorylated STAT1, the dsNLS can only act as a nuclear import signal within the context of phosphorylated STAT1. In addition, STAT1 can heterodimerize with STAT2 and STAT3 [67], and requires the dsNLS in the DNA-binding domain to accumulate in the nucleus. Interestingly, STAT2 cannot form homodimers or enter the nucleus on its own, suggesting that the dsNLS is a unique to STAT1 or STAT1-associated complexes [75].

\section{Phosphorylation unmasks an NLS through disruption of an NES}

The extracellular signal regulated kinase (ERK) cascade has an important role in cellular development and phase transitions in the cell cycle [76]. The cytoplasmic bottleneck of this cascade is the ERK kinase, which accumulates in the nucleus 15 minutes after the mitogenic stimulus, and phosphorylates transcription factors critical for development [77]. ERK5 is an important member of the MAP kinase family that stimulates the transcriptional activity of c-Fos, c-Myc, MEF2 and numerous other factors involved in cardiovascular development and S-phase entry [76-79]. ERK5 (also termed Big MAP Kinase) is the largest of the ERK family members as it contains an extended C-terminal domain with two proline-rich regions, a transcriptional activation domain (TAD), and a bipartite NLS (Figure 1B), in addition to its $\mathrm{N}$-terminal kinase domain [80]. Interestingly, ERK5 does not display a classical NES, but undergoes Crm1mediated nuclear export $[81,82]$. Similar to the STAT1 dimer-specific NLS, ERK5 displays a conditional NES that only acts in cis [83]. In resting cells, the ERK5 $\mathrm{N}$ - and C-termini interact, which conceals the bipartite NLS, and creates an interface for Crm1 recognition [83]. The Map Kinase Kinase of ERK5 (MEK5) disrupts the ERK5 termini-dependent binding interface through phosphorylation of tyrosine and threonine residues in the Thr-Glu-Tyr (TEY) activation motif [84]. Upon phosphorylation, the putative NES is silenced, thereby exposing the bipartite NLS in the C-terminus, and hence promoting ERK5 nuclear accumulation [83]. It is unclear whether the ERK5 NES region recruits Crm1 directly, or via another NES-containing binding partner. Undoubtedly, phosphorylation plays a role in the nuclear import of ERK5 by altering the balance between NLS/NES signaling. In addition to multi-domain regulation of ERK5 nuclear transport, the $\mathrm{N}$ - and $\mathrm{C}$-terminal domains are essential for transactivation of the transcription factor AP-1 [80]. AP-1 controls a number of cellular processes including proliferation, differentiation, and apoptosis. Upon activation, the ERK5 N-terminal kinase domain auto-phosphorylates the ERK5 C-terminal TAD, which has been shown to increase the transcriptional activity of AP-1 20-fold [80]. When expressed in the absence of the ERK5 kinase domain, the ERK5 TAD has no affect on AP-1 transcription. Notably, ERK5 is the only known cellular target of MEK5, and overexpression of MEK5 is associated with aggressive prostate cancer [85], cellular hypertrophy in cardiomyocytes [86], and impaired angiogenesis [87]. Thus, ERK5 phosphorylation plays a critical role in the coordination of inter- and intra-molecular binding interactions responsible for regulation of numerous cellular processes.

\section{Phosphorylation activates non-canonical transport signals that mediate nuclear import}

In addition to basic NLSs (Figure 1B), several other small epitopes have been identified that when phosphorylated can promote nuclear import. For the purpose of this review, we will discuss two examples of these phosphorylation-activated transport signals: 1) the Nuclear Transport Signal (NTS) of ERK1/2 and 2) the arginine/serine (RS) dipeptide repeats of serine/argininerich proteins (SR proteins). The ERK family members ERK1 and ERK2 play a critical role in cellular development and cell cycle regulation. ERK1 and ERK2 are the cytoplasmic targets of the Ras-Ref-MEK-ERK signaling network, responsible for driving cellular proliferation through activation of transcription factors such as Fos and Elk-1 [88]. The MAPKK MEK1/2 is responsible for the activation of ERK1 and ERK2 [89]. Interestingly, MEK1/2 acts as a scaffold protein for ERK1/2, and anchors ERK in the cytoplasm under non-stimulating conditions $[90,91]$. Upon activation, MEK1/2 phosphorylates ERK1/2 at a TEY motif, which induces a conformational change in ERK1/2 and leads to its dissociation from MEK1/2 (Figure 4A). Until recently, the details of ERK1/2 nuclear transport were unclear. Unlike ERK5, which displays a bipartite NLS in its C-terminus [80], no obvious NLS or NES are discernable in the ERK1/2 primary sequence. Initially, it was believed that phosphorylated ERK1/2 entered the nucleus passively as a monomer, and that its more rapid, energy-dependent transport could involve dimerization and direct interaction with the NPC [92-94]. Recently, a novel NTS was identified for ERK1/2 in its kinase insert domain (Figure 1 ), which contains a characteristic Ser-Pro-Ser (SPS) motif. Upon stimulation, the SPS is phosphorylated and becomes functionally active. The phosphorylated motif is recognized by the nuclear transport receptor importin $\beta 7$ [95] (Figure 4A), also a $\beta$-karyopherin implicated in the nuclear transport of two other proteins, MEK1 and SMAD3, which also contain SPS or TPT motifs $[95,96]$. Highlighting the importance of tightly regulated ERK1/2 phosphorylation in human biology, upregulation of MEK1/2 in brain tissue is linked to neurofibrillary degeneration in Alzheimer's disease [97]. 


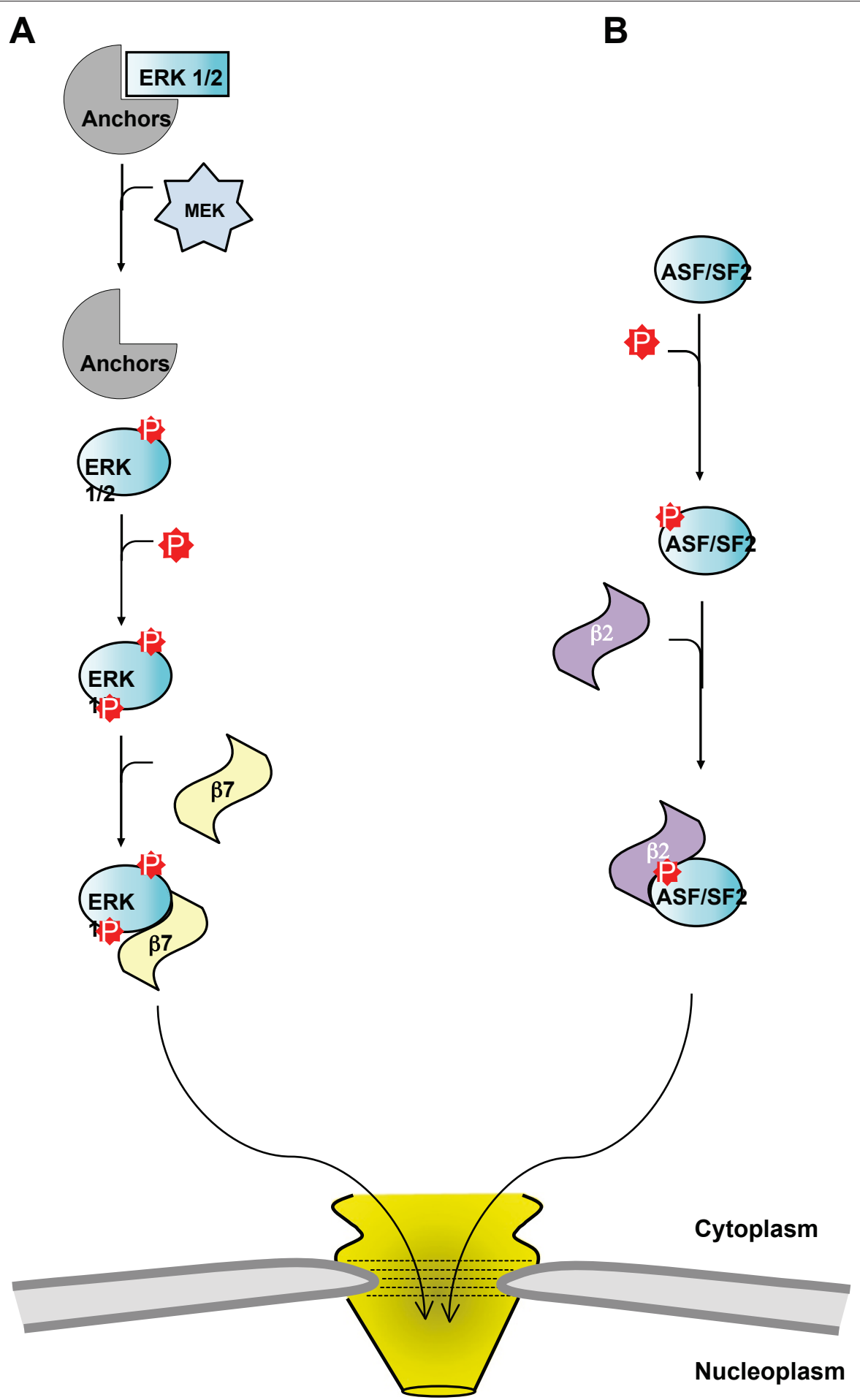

Figure 4 Schematic representation of two phosphorylation-activated transport signals that confer nuclear import independent of importin $\boldsymbol{\beta 1}$. (A) ERK1/2 (cyan) is sequestered in the cytoplasm by anchoring proteins (shown in grey). Upon phosphorylation at its TEY site, ERK $1 / 2$ undergoes a conformational change, causing it to dissociate from the anchoring proteins. This allows MEK access to the NTS which it phosphorylates. Upon NTS phosphorylation, ERK1/2 is recognized and imported into the nucleus by importin $\beta 7$ (yellow). (B) The SR protein ASF/SF2 (cyan) is phosphorylated at Arg-Ser (RS) dipeptide repeats that function as an NLS for the import receptor importin $\beta 2$ (also known as transportin), shown in purple. 
Similar to NTS-containing proteins, serine/argininerich (SR) proteins rely on phosphorylation-dependent recognition of a small epitope for their nuclear import. SR proteins are fundamental to mRNA metabolism in the nucleus [98], and cycle between the cytoplasm and nucleoplasm depending on the level of transcription [99]. The prototypical SR protein ASF/SF2 is essential to genome stability, and depletion of this factor in metazoa was shown to induce G2 cycle arrest and apoptosis $[100,101]$. The RS domain of ASF/SF2 spans the Cterminal residues 198-248, and contains a series of ArgSer (RS) dipeptide repeats that can function as an NLS $[99,102]$. Interestingly, the RS-motif is only functional as an NLS when phosphorylated, as unphosphorylated ASF/SF2 localizes to the cytoplasm [103,104]. The importin $\beta$-like nuclear transport receptor importin $\beta 2$ (also known as transportin) contains a unique internal domain responsible for the recognition of phosphorylated SR proteins [103,104] (Figure 4B). Like for importin $\beta-1$, nuclear import of phosphorylated SR proteins by importin $\beta 2$ is expected to be regulated by RanGTP. With further investigation into the role of phosphorylation in nuclear transport, it is likely that various signaling clusters similar to the non-canonical NLSs of ERK1/ 2 and ASF/SF2 will be identified.

\section{Down-Regulation of Nuclear Import by Phosphorylation}

A phosphorylation-sensitive component of the nuclear transport machinery controls nuclear import

While phosphorylation of the nuclear envelope and NPC are necessary steps in cell cycle progression and the onset of mitosis, phosphorylation of the nuclear transport machinery in resting cells has a dramatic inhibitory effect on nuclear import. Kehlenbach et al. investigated the effect of phosphatase and kinase inhibitors on the nuclear transport of NLS-bearing cargos in a nuclear transport assay in digitonin-permeabilized cells [105]. This technique involves permeabilizing the cell membrane without disrupting the nuclear envelope so that the endogenous cytosol (soluble cellular proteins and transport factors) can be washed away and replaced with a controlled nuclear transport reaction mixture (e.g. purified importins, energy, etc.) [42] This allows dissecting the effect of individual components of the nuclear transport machinery on the nuclear transport of NLS- or NES-containing cargos. Kehlenbach et al. showed that the phosphatase inhibitors Okadoic Acid (OA) and microcystin dramatically inhibit nuclear import pathways mediated by transportin and importin $\beta$. Treatment with the broad-spectrum kinase inhibitor, staurosporine, was able to partially reverse the import inhibition, thereby suggesting that staurosporine-resistant kinases are also involved in the inhibition. They concluded that the phosphorylation targets were most likely nucleoporins in the NPC central channel because OA did not affect karyopherin recognition of NLS-cargo or the cellular localization of RanGTP. In addition, they suggested that the responsible kinases were both membrane associated and cytoplasmic. Interestingly, a recent investigation of the Picornaviruses EMCV and Theiler's murine encephalomyelitis virus showed the negative effects of the Leader protein (L-protein) on the nuclear transport machinery. The L-protein blocks nuclear transport in two known ways: 1) direct binding of Ran, which leads to misregulation of its activity [106], and 2) upregulation of cellular kinases, leading to the hyperphosphorylation of nucleoporins (specifically Nup62, Nup214, and Nup153) [107]. It will be interesting to define the exact kinase(s) responsible for Nup hyperphosphorylation, and whether the same kinase(s) is involved in the regulation of nuclear transport under normal physiological conditions.

\section{Cytoplasmic retention of cellular cargos by direct phosphorylation of an NLS}

A simple way to retain cargos in the cytoplasm is by inactivating the NLS. This can be achieved either by direct binding and sequestering of the NLS, like the inhibitory protein of NF-kB (IKB) [108], or by phosphorylation of certain residues within the NLS. The latter is well documented for at least five cargos, two in humans and three in budding yeast, which will be discussed here.

The nuclear factor of activated T-cells (NFAT) is a well-characterized example of cargo retained in the cytoplasm by a phosphorylation in its NLS. First identified as a critical transcription factor for T-cell activity $[109,110]$, NFAT is involved in numerous biological processes including the growth and development of muscle and neuronal cells as well as the immune response. There are four NFAT family members, which share highly conserved DNA-binding domains and serine- and proline-rich regions [110,111]. NFAT activity it tightly regulated by kinases and phosphatases in a calciumdependent manner. Under normal physiological conditions, NFAT is localized to the cytoplasm due to phosphorylation of its serine-rich region (SRR2) [112], which overlaps with the NFAT NLS (Figure 1C). In addition to kinases that sequester NFAT in the cytoplasm, NFAT also contains a strong NES for Crm1mediated nuclear export, which aids in its cytoplasmic localization [113]. Elevated cellular $\mathrm{Ca}^{2+}$ levels stimulate Calcineurin, a $\mathrm{Ca}^{2+}$ dependent serine phosphatase, which then binds to NFAT and dephosphorylates the NLS, making it accessible for recognition by the nuclear import machinery [114]. A drop in $\mathrm{Ca}^{2+}$ levels or inactivation of Calcineurin by CsA or FK506, results in the 
phosphorylation of the NFAT NLS [115], which inhibits its nuclear accumulation. Calcineurin is a popular target of immunosuppressive drugs because its inactivation inhibits the ability of NFAT to enter the nucleus and stimulate an immune response. In addition to its role in the immune response, precise Calcineurin/NFAT signaling is required for axonal outgrowth of embryonic neurons [116], a process tightly linked to memory and learning [117].

The second important example of phosphorylationmediated down-regulation of nuclear import that has important physiological consequences in humans is the parathyroid hormone related protein (PTHrP). This small secreted protein is best known for its role in chondrocyte maturation, but it is also expressed in a range of tumors as it has fundamental roles in cell cycle control and apoptosis $[118,119]$. The PTHrP gene yields three distinct alternative splice products, in a tissue specific manner that can display both paracrine and intracrine activities [120]. Its paracrine characteristics are attributed to the $\mathrm{N}$-terminus of PTHrP, which is highly homologous to the secreted peptide hormone $\mathrm{PTH}$, while PTHrP intracrine activities in the nucleus rely on its C-terminus [121]. After internalization by receptormediated endocytosis, PTHrP is rapidly transported into the nucleus, where it is involved in accelerating cell cycle and cell proliferation [122]. PTHrP displays a long non-classical NLS (ncNLS) between residues 66-97 (Figure 1C), which is recognized directly by importin $\beta$, independent of importin $\alpha$ [123]. Structural studies in complex with an $\mathrm{N}$-terminal fragment of importin $\beta$ revealed that the PTHrP-ncNLS binds HEAT repeats 2-11 of importin $\beta$ HEAT, which are also responsible for binding to RanGTP and importin $\alpha$ [40]. The nuclear import of PTHrP is down regulated by the cell cycle-dependent kinases p33 and p34, which phosphorylate Thr85 in the ncNLS (Figure 1C) [124]. Interestingly, in the crystal structure of PTHrP-ncNLS bound to importin $\beta$, the site of phosphorylation at $\mathrm{Thr}^{85}$ is located in close proximity to two well conserved tryptophan residues of importin $\beta$, which are known to be important for nuclear import of classical NLS cargos [125]. A phosphate moiety at this position could disrupt the interaction of the tryptophan side chains with the PTHrP-ncNLS, likely reducing the binding affinity for importin $\beta$ and hence down-regulating nuclear import of PTHrP. However, since PTHrP is small enough to diffuse into the nucleus, phosphorylation in this case only slows down and does not completely obliterate the biological effect of PTHrP.

The transduction of extracellular signals to the nucleus displayed by higher eukaryotes occurs through analogous pathways in lower eukaryotes. Not surprisingly, phosphorylation plays a critical role in this process. The cellular localization of the transcription factor Msn2p in Saccharomyces cerevisiae is highly sensitive to stress response elements (STREs) [126]. Activation of Msn2p leads to the up-regulation of over 150 genes responsible for coping with environmental stresses such as osmotic shock, oxidative damage, chemical insult, and heat and nutrient depravation [127]. In particular, Msn2p nuclear transport under nutrient deprived conditions is regulated by the cAMP-dependent protein kinase (cAPK). The C-terminus of Msn2p contains four arginine- and lysine-rich clusters that function as a classical NLS [128]. These clusters overlap with serine phosphorylation sites (RRXS) targeted by cAPK (Figure 1C). Under normal physiological conditions, Msn2p is restricted to the cytoplasm due to phosphorylation of one or more of its basic clusters by CAPK, which inhibits importin $\alpha$ recognition and thus nuclear import of Msn2p [129]. Under glucose-deprived conditions, cAPK is down regulated, which leads to the accumulation of unphosphorylated Msn2p in the nucleus, and ultimately a transcriptional response to extracellular stress.

Similar to Msn2p, phosphorylation-mediated down regulation of nuclear import has been described for the S. cerevisiae transcription factor Pho4. Budding yeast has an extensive network of proteins involved in regulation of inorganic phosphate availability [130]. Upon phosphate starvation, dephosphorylated Pho4 is recruited to the nucleus where it in turn activates genes that respond to the levels of cellular phosphate [131]. When there is a supply of inorganic phosphate available to the cell, Pho4 is phosphorylated on five separate serine/proline motifs [132]. Two of these motifs are required for nuclear export, as binding to Pho4's export factor, Msn5, is strictly dependent on the phosphorylation state $[131,133]$. A third serine/proline phosphate site is contained within Pho4's NLS (Figure 1C). Upon phosphorylation, the import factor Pse1 is no longer able to bind to Pho4 $[131,133]$. Together, the increase in nuclear export signal potency and hindrance of nuclear import synergize to assure that Pho4 is retained in the cytoplasm during times of inorganic phosphate availability.

Another example of down-regulation of nuclear import by phosphorylation was reported for the S. cerevisiae transcription factor Swi6. Swi6p regulates the expression of several genes during the G1 phase of the cell cycle $[134,135]$, when it enters the nucleus by active signal-mediated transport. Interestingly, hypophosphorylation of serine 160 of Swi6p located immediately upstream of the NLS correlates with Swi6p nuclear import [135] (Figure 1C). In contrast, hyperphosphorylation of serine 160 during the other phases of the cell cycle correlates with cytoplasmic localization [135]. Thus, the cell cycle-dependent phosphorylation of Swi6p 
correlates with its localization, and ultimately expression of downstream genes [135]. Using in vitro solution binding assays, Harreman et al. demonstrated that phosphorylation of serine 160 upstream of Swi6-NLS causes a 4-fold decreased binding affinity between the Swi6 and importin $\alpha 1$ [136]. A similar drop in affinity for observed by replacing serine 160 with a glutamic acid (S160E-NLS), which functions as a phosphomimetic. In addition, a GFP-tagged Swi6 S160E-NLS mutant showed a decreased rate of nuclear import when compared to wild type GFP-Swi6-NLS supporting the hypothesis that phosphorylation directly adjacent to an NLS decreases the binding affinity for importin $\alpha 1$, which correlates with reduced nuclear import efficiency of the phosphorylated cargo.

\section{Role of Phosphatases in Regulating Phosphorylation-Dependent Nuclear Transport of Stat 1}

Cellular Phosphatases target STAT1

Because STAT1 is the most well studied example of phosphorylation-dependent nuclear transport, there has been much interest in the identification of phosphatases that counteract STAT1 activation. IFN signaling cascades undergo rapid activation-inactivation cycles that require tight regulation. The IFN $\gamma$ signaling pathway is negatively regulated in at least three ways: 1 ) suppressors of Cytokine Signaling inhibition of JAKs and the IFN $\gamma$ receptor at the cell membrane [137], 2) nuclear localization of the Protein Inhibitor of STAT1 factor [138], and 3) tyrosine and dual-specificity phosphatases that dephosphorylate STAT1 at $\mathrm{Tyr}^{701}$. One of the first phosphatases identified in the regulation of STAT signaling was the $\mathrm{T}$-cell protein tyrosine phosphatase (TCPTP). The TC-PTP gene is alternatively spliced, yielding a longer ER-associated form TC48, and a nuclear form TC45 $[139,140]$. The nuclear form of TC-PTP is responsible for the cooperative deactivation of STAT1 when it is released from target DNA [141]. Upon dephosphorylation by TC45, STAT1 undergoes Crm1-mediated nuclear export and participates in successive activationinactivation cycles in stimulated cells [142]. In addition to its role in STAT1 deactivation, TC45 has also been implicated in the dephosphorylation of STAT3 in the nucleus.

The Src homology domain (SHP) family of dual-specificity phosphatases (SHP-1 and SHP-2) also plays a regulatory role in STAT nuclear localization; SHP's have a unique dephosphorylation mechanism, utilizing two tandem N-terminal SH2-domains (N-SH2 and C-SH2), a tyrosine phosphatase (PTP) domain and two C-terminal Tyr phosphorylation sites. Structural investigations of SHP-2 reveal an auto-inhibitory mechanism of the PTP domain by the $\mathrm{N}-\mathrm{SH} 2$ in the absence of a $\mathrm{pTyr}$ substrate [143]. When the $\mathrm{C}-\mathrm{SH} 2$ domain recognizes a bipartite pTyr ligand it binds one pTyr, and the N-SH2 domain binds the other pTyr, reversing the autoinhibition of the phosphatase. The SHP Tyr residues in its $\mathrm{C}$-terminus can also represent the bipartite ligand when these residues are phosphorylated. While SHP-1 is primarily expressed in hematopoetic cells, SHP-2 is constitutively expressed in most cell types, and regulates a number of pathways including JAK/STAT, MAP Kinase, $\mathrm{NF} \kappa \mathrm{B}$, and PI3 kinase [144]. SHP-2 negatively regulates the JaK/STAT pathway through dephosphorylation of a number of receptor tyrosine kinases at the cell membrane [67], Jak2 in the cytoplasm [145], and STAT1 in the nucleus [146]. Each of these substrates contains two or more proximal phospho-tyrosine residues most likely targeted by the SHP domain architecture. The examples described above only represent a few of the many ways that native phosphatases maintain balance within the Jak/STAT pathway, and control the nuclear transport of STAT1.

\section{Viral Phosphatases target cytokine signaling pathways}

Out of necessity, viruses have developed a number of mechanisms to evade the host innate immune response and neutralize cytokine signaling pathways, specifically the Jak/STAT pathway. Many virus families encode enzymes responsible for the evasion of host defense mechanisms, but few viruses like Poxviridae (e.g. vaccinia, variola virus etc) are known to encode phosphatases. Members of the Poxviridae family of double stranded DNA viruses carry a large, linear, genome of approximately $200-\mathrm{kbp}$, and assemble entirely in the cytoplasm of host cells [147]. Poxviridae encodes the dual-specificity phosphatase VH1, which is highly conserved among poxviruses and essential for the viability of Vaccinia virus in tissue cultures [148]. VH1 is expressed in late-stage of viral infection and an estimated 200 copies of $\mathrm{VH} 1$ are packaged within the virion [148]. VH1 has at least two important functions in the Vaccinia virus lifecycle: first, it dephosphorylates twovirion membrane-associated factors A17 [149] and A14 [150], in vivo. Second, VH1 was shown to deactivate host IFN $\gamma$ signaling through dephosphorylation of specific tyrosine and serine residues required for STAT1 nuclear import and transcriptional activity [151]. It has been proposed that VH1 targets phosphorylated STAT1 (pSTAT1) in the cytoplasm as pSTAT1 bound to DNA is resistant to VH1 dephosphorylation, in vitro [152]. Moreover, STAT1's dedicated import adaptor importin $\alpha 5$ efficiently competes with VH1 for STAT1 dephosphorylation, suggesting both importin $\alpha 5$ and VH1 encounter PSTAT1 in the cytoplasm prior to its nuclear import [152]. Dephosphorylation of STAT1 at Try701 blocks carrier mediated nuclear accumulation of STAT1 


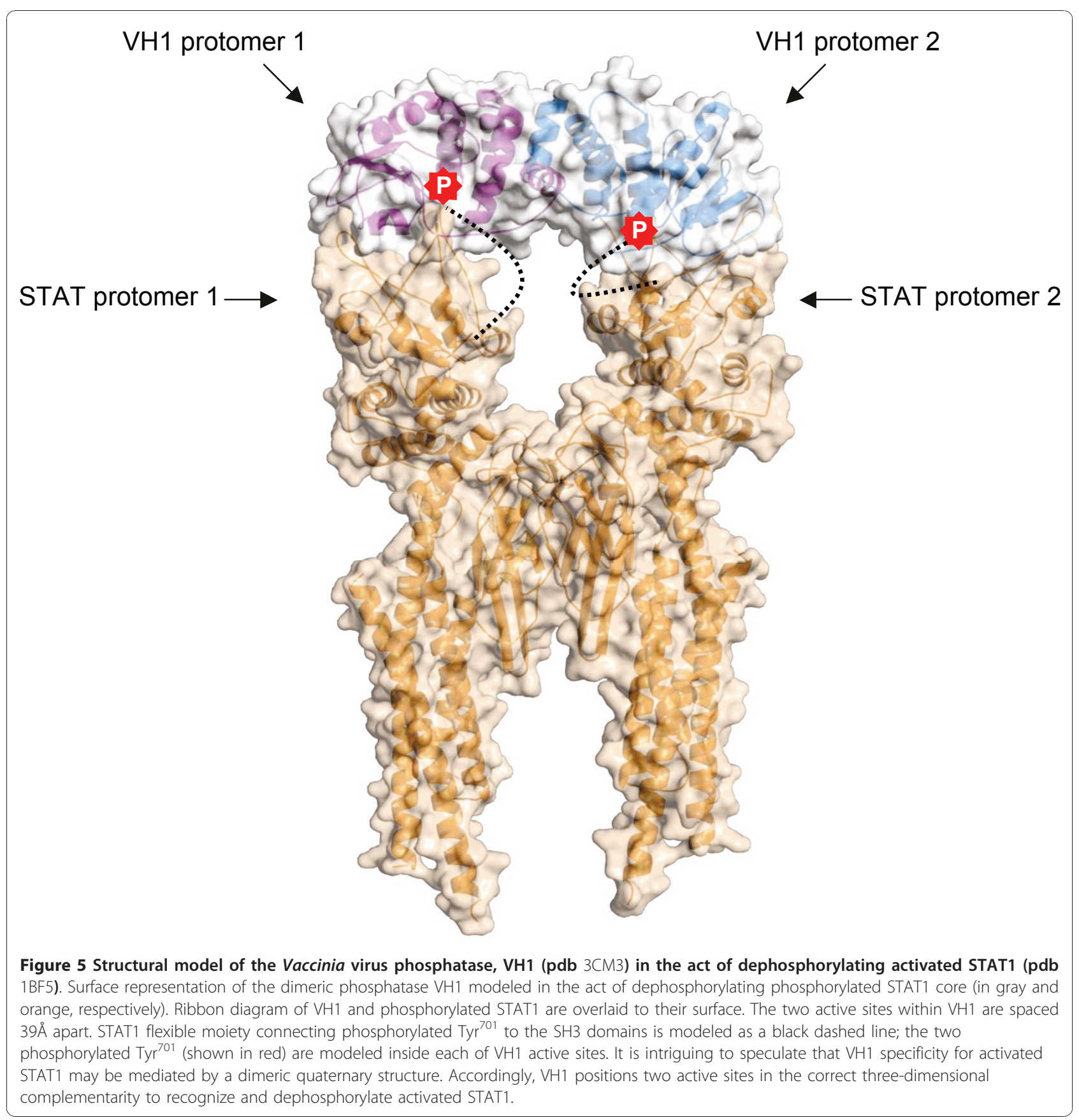

[19] but does not affect the carrier independent import of unphosphorylated STAT1, which occurs via direct binding to nucleoporins [153]. Like phosphorylated STAT1 [69], VH1 displays a dimeric quaternary structure [152]. Interestingly, the active sites of the $\mathrm{VH} 1$ monomers are spaced $39 \AA$ apart, which is equal to the distance between the phospho-Tyr residues seen in the crystal structure of pSTAT1 bound to DNA [63]. This raises the intriguing possibility that VH1 dimeric quaternary structure has been specifically evolved as a dedicated solution to optimize recognition and dephosphorylation of STAT1 (Figure 5). This, in turn, prevents nuclear import of STAT 1 and transcription of interferon- $\gamma$ genes, thereby blocking the antiviral response.

In the past decade, an increasing number of phosphatases have been implicated in the deactivation of JaK/ STAT signaling through the dephosphorylation of STAT1 or its upstream effectors. For example, two Flaviviruses, the mosquito-borne flavivirus JEV and the tick-borne TBE both encode the protein NS5, which 
was shown to disrupt IFN signaling. While NS5 does not display a structurally conserved phosphatase motif, treatment of infected cells with the PTP inhibitor sodium orthovanadate restored IFN $\gamma$ and IFN $\alpha$ signaling $[154,155]$. This suggests that although NS5 is not a phosphatase itself, it may function by upregulating the activity of endogenous phosphatases that dephosphorylate members of the JaK/STAT pathway. A recent investigation of the Dengue virus NS5 protein and STAT2 showed that NS5 directly binds STAT2, inhibiting STAT2 phosphorylation and IFN $\alpha$ signaling (mediated by STAT1/2 heterodimers) [156], but this effect did not affect IFN $\gamma$ signaling (mediated by STAT1 homodimers). Although it remains unclear how Flavivirus-specific NS5 proteins inhibit IFN signaling pathways, one shared characteristic seen in different viruses is that evasion of the immune response occurs by blocking STAT nuclear import, and hence, STAT-mediated antiviral response.

\section{Conclusions}

It has been 55 years since the groundbreaking study on the conversion of phosphorylase $b$ to phosphorylase $a$, by Fisher and Krebs, that first emphasized the importance of reversible phosphorylation in biology [157]. Today, we know that phosphorylation is the key regulatory step in signaling pathways responsible for cellular development and differentiation, cell cycle control, metabolism, and the immune response. It acts not only as a veritable on and off switch for protein activity, but also as a precise mechanism of redirecting a protein's cellular localization, and thus its function in the cell. As described in this review, the role of phosphorylation in the nuclear transport of cargos has only now begun to be elucidated. We have discussed key examples of the different mechanisms by which this occurs. In this final section, we will try to summarize the broad significance of this novel regulatory mechanism. Although the phosphorylated cargos described in this review are seemingly diverse, some general rules emerge comparing their function. Nearly all known cargos whose nuclear import is regulated by phosphorylation act directly (or indirectly) on the control of gene expression. Certain cargos are transcription factors (e.g. STAT1, NFAT, Msn2p, Pho4, Swi6) that directly bind DNA and trigger expression of critical genes, or kinases that specifically phosphorylate transcription factors critical for development (e.g. ERK proteins). Other cargos (mainly viral) function as transactivators of genome transcription (EBNA-1), or like SV40 T-large antigen, bind to important cellular proteins such as $\mathrm{p} 53$ and retinoblastoma protein $(\mathrm{pRb})$, and thereby are capable of transforming a variety of cell types. Finally, other cargos such as SR proteins or PTHrP [158] are linked to RNA metabolism. Thus, phosphorylation of these import cargos alters their nuclear availability and thereby functions as a liaison between extracellular stimuli and gene expression in the nucleus. This provides a novel and useful level of regulation that allows turning genes on and off when cellular and developmental conditions demand it. By controlling the availability of transcription factors in the nucleus, cells respond to extracellular stimuli and trigger proliferation or defense mechanisms. Intuitively, the regulation of nuclear import and nuclear availability of transcription factors and certain proteins that directly affect gene expression is vital for cell proliferation and linked to human disease. For instance, STAT1 is becoming increasingly important in cancer biology [159-163]. Although the IFN- $\gamma /$ STAT1 signaling is usually connected with anti-viral response and pro-apoptotic tumor-suppressor functions, constitutively activated IFN- $\gamma /$ STAT1 pathway has been recently associated with aggressive tumor phenotypes [163]. For instance, high level of nuclear phosphorylated STAT1 is hallmark of resistance to IFN- $\gamma$ and radiation therapy, which is commonly acquired during radiotherapy treatment and accounts for many treatment failures [160]. In this respect, nuclear entry of activate STAT1 is also of potential pharmacological interest. Small molecule inhibitors that reduce accumulation of phosphorylated STAT1 in the nucleus would function as useful anticancer agents and likely prevent radiation resistance. Similarly, PTHrP's role as a growth/malignancy factor clearly correlates to its ability to localize in the nucleus/nucleolus and thereby delay apoptosis [158]. In conclusion, there is little doubt that phosphorylation adds another level of regulation to the already tightly control trafficking of proteins between the nucleus and cytoplasm. The challenge is now to expand the analysis of import cargos that are phosphorylated and develop more quantitative methods to measure how phosphorylation affects the kinetic of nuclear localization as well as protein turnover, in vivo. This is likely to have a very significant impact on our ability to understand how extracellular stimuli (e.g. cytokines, hormones, environmental stress) affect, modulate and control gene expression in the cell nucleus.

\section{List of Abbreviations used}

NLS: nuclear localization signal; NPC: nuclear pore complex; NE: nuclear envelope; ONM: outer nuclear membrane; INM: inner nuclear membrane; IBB: importin $\beta$ binding; NES: nuclear export signal; NUP: nucleoporin; EBV: Epstein-Barr virus; EBNA-1: Epstein-Barr virus nuclear antigen 1; HBV: Hepatitis $B$ virus; PKC: protein kinase C; STATs: signal transducers and activators of transcription; SH2: Src2 Homology domain; dsNLS: dimer-specific NLS; CNLS: classical NLS; ncNLS: non classical NLS; ARM: armadillo; ERF: extracellular signal regulated kinase; TAD: transcriptional activation domain; TEY: Thr-GluTyr; NTS: Nuclear Transport Signal; SR protein: serine/arginine-rich proteins; SPS: Ser-Pro-Ser; OA: okadoic acid; IKB: inhibitory protein of NF-kB; NFAT; nuclear factor of activated T-cells; SRR2: serine-rich region; PTHrP: parathyroid hormone related protein; STREs: stress response elements; CAPK: CAMP- 
dependent protein kinase; TC-PTP: T-cell protein tyrosine phosphatase; PTP: protein tyrosine phosphatase; SHP: SH2-containing tyrosine phosphatase; PSTAT1: phosphorylated STAT1; IFN: interferon; JaK: Janus Kinase; PIAS: Protein Inhibitor of STAT1; SOCS: Suppressor of Cytokine Signaling; VH1: Vaccinia virus H1 gene product; JEV: Japanese Encephalitis Virus; TBE: TickBorne Encephalitis Virus.

\section{Acknowledgements}

This work was supported by NIH grant GM074846-01A1 to GC. We apologize to all authors whose work could not be cited in this review due to lack of space. Where possible, reviews have been referenced instead of the original research papers.

\section{Author details}

${ }^{1}$ Dept. of Biochemistry and Molecular Biology, SUNY Upstate Medical University, 750 E. Adams Street, Syracuse, NY 13210, USA. ${ }^{2}$ Dept. of Biochemistry and Molecular Biology, Thomas Jefferson University, 233 South 10th Street, Philadelphia, PA 19107, USA.

\section{Authors' contributions}

$J N$ wrote the initial draft of the manuscript; $K L$ expanded and revised the manuscript, and generated all figures. GC revised both text and figures critically for important intellectual content; all three authors have given final approval of the version to be published.

\section{Competing interests}

The authors declare that they have no competing interests

Received: 30 September 2010 Accepted: 23 December 2010 Published: 23 December 2010

\section{References}

1. Strambio-De-Castillia C, Niepel M, Rout MP: The nuclear pore complex: bridging nuclear transport and gene regulation. Nat Rev Mol Cell Biol 11:490-501.

2. Mosammaparast N, Pemberton LF: Karyopherins: from nuclear-transport mediators to nuclear-function regulators. Trends Cell Biol 2004, 14:547-556.

3. Gorlich D, Kutay U: Transport between the cell nucleus and the cytoplasm. Annu Rev Cell Dev Biol 1999, 15:607-660.

4. Stewart M: Molecular mechanism of the nuclear protein import cycle. Nat Rev Mol Cell Biol 2007, 8:195-208.

5. Pemberton LF, Paschal BM: Mechanisms of receptor-mediated nuclear import and nuclear export. Traffic 2005, 6:187-198.

6. Lange A, Mills RE, Lange CJ, Stewart M, Devine SE, Corbett AH: Classical nuclear localization signals: definition, function, and interaction with importin alpha. J Biol Chem 2007, 282:5101-5105.

7. Kaffman A, O'Shea EK: Regulation of nuclear localization: a key to a door. Annu Rev Cell Dev Biol 1999, 15:291-339.

8. Chook YM, Blobel G: Karyopherins and nuclear import. Curr Opin Struct Biol 2001, 11:703-715.

9. Gorlich D, Dabrowski M, Bischoff FR, Kutay U, Bork P, Hartmann E, Prehn S, Izaurralde E: A novel class of RanGTP binding proteins. J Cell Biol 1997, 138:65-80

10. Richards SA, Carey KL, Macara IG: Requirement of guanosine triphosphatebound ran for signal-mediated nuclear protein export. Science 1997, 276:1842-1844

11. Moroianu J, Blobel G: Protein export from the nucleus requires the GTPase Ran and GTP hydrolysis. Proc Natl Acad Sci USA 1995, 92:4318-4322.

12. Ohtsubo M, Okazaki H, Nishimoto T: The RCC1 protein, a regulator for the onset of chromosome condensation locates in the nucleus and binds to DNA. J Cell Biol 1989, 109:1389-1397.

13. Matunis MJ, Wu J, Blobel G: SUMO-1 modification and its role in targeting the Ran GTPase-activating protein, RanGAP1, to the nuclear pore complex. J Cell Biol 1998, 140:499-509.

14. Harel A, Forbes DJ: Importin beta: conducting a much larger cellular symphony. Mol Cell 2004, 16:319-330.

15. Lott K, Bhardwaj A, Mitrousis G, Pante N, Cingolani G: The importin beta binding domain modulates the avidity of importin beta for the nuclear pore complex. J Biol Chem 2010, 285:13769-13780.
16. Lott K, Cingolani G: The IBB Domain as a Master Regulator of Nucleocytoplasmic Transport. Biochimica et biophysica acta 2010.

17. Goldfarb DS, Corbett AH, Mason DA, Harreman MT, Adam SA: Importin alpha: a multipurpose nuclear-transport receptor. Trends Cell Biol 2004, 14:505-514.

18. Mason DA, Stage DE, Goldfarb DS: Evolution of the metazoan-specific importin alpha gene family. J Mol Evol 2009, 68:351-365.

19. Meyer T, Vinkemeier U: Nucleocytoplasmic shuttling of STAT transcription factors. Eur J Biochem 2004, 271:4606-4612.

20. Tarendeau F, Boudet J, Guilligay D, Mas PJ, Bougault CM, Boulo S, Baudin F, Ruigrok RW, Daigle N, Ellenberg J, et al: Structure and nuclear import function of the C-terminal domain of influenza virus polymerase PB2 subunit. Nat Struct Mol Biol 2007, 14:229-233.

21. Fagerlund R, Kinnunen L, Kohler M, Julkunen I, Melen K: NF-\{kappa\}B is transported into the nucleus by importin \{alpha\} 3 and importin \{alpha\}4. J Biol Chem 2005, 280:15942-15951.

22. Lee BJ, Cansizoglu AE, Suel KE, Louis TH, Zhang Z, Chook YM: Rules for nuclear localization sequence recognition by karyopherin beta 2 . Cell 2006, 126:543-558

23. Lim RY, Ullman KS, Fahrenkrog B: Biology and biophysics of the nuclear pore complex and its components. Int Rev Cell Mol Biol 2008, 267:299-342.

24. Brohawn SG, Partridge JR, Whittle JR, Schwartz TU: The nuclear pore complex has entered the atomic age. Structure 2009, 17:1156-1168.

25. D'Angelo MA, Hetzer MW: Structure, dynamics and function of nuclear pore complexes. Trends Cell Biol 2008, 18:456-466.

26. Drummond $\mathrm{S}$, Allen T: Structure, function and assembly of the nuclear pore complex. Symp Soc Exp Biol 2004, 89-114.

27. Yaseen NR, Blobel G: Two distinct classes of Ran-binding sites on the nucleoporin Nup-358. Proc Natl Acad Sci USA 1999, 96:5516-5521.

28. Walther TC, Fornerod M, Pickersgill H, Goldberg M, Allen TD, Mattaj IW: The nucleoporin Nup153 is required for nuclear pore basket formation, nuclear pore complex anchoring and import of a subset of nuclear proteins. Embo J 2001, 20:5703-5714.

29. Terry LJ, Wente SR: Flexible gates: dynamic topologies and functions for FG nucleoporins in nucleocytoplasmic transport. Eukaryot Cell 2009, 8:1814-1827.

30. Patel SS, Belmont BJ, Sante JM, Rexach MF: Natively unfolded nucleoporins gate protein diffusion across the nuclear pore complex. Cell 2007, 129:83-96

31. Peters R: Translocation through the nuclear pore complex: selectivity and speed by reduction-of-dimensionality. Traffic 2005, 6:421-427.

32. Tran EJ, Wente SR: Dynamic nuclear pore complexes: life on the edge. Cell 2006, 125:1041-1053.

33. Weis K: The nuclear pore complex: oily spaghetti or gummy bear? Cell 2007, 130:405-407.

34. Deribe YL, Pawson T, Dikic I: Post-translational modifications in signal integration. Nat Struct Mol Biol 17:666-672.

35. Lin J, Xie Z, Zhu H, Qian J: Understanding protein phosphorylation on a systems level. Brief Funct Genomics 9:32-42.

36. Shi Y: Serine/threonine phosphatases: mechanism through structure. Cell 2009, 139:468-484

37. Hunter T: Protein kinases and phosphatases: the yin and yang of protein phosphorylation and signaling. Cell 1995, 80:225-236.

38. Moorhead GB, Trinkle-Mulcahy L, Ulke-Lemee A: Emerging roles of nuclear protein phosphatases. Nat Rev Mol Cell Biol 2007, 8:234-244.

39. Arnold M, Nath A, Hauber J, Kehlenbach RH: Multiple importins function as nuclear transport receptors for the Rev protein of human immunodeficiency virus type 1. J Biol Chem 2006, 281:20883-20890.

40. Cingolani G, Bednenko J, Gillespie MT, Gerace L: Molecular basis for the recognition of a nonclassical nuclear localization signal by importin beta. Mol Cell 2002, 10:1345-1353.

41. Jakel S, Albig W, Kutay U, Bischoff FR, Schwamborn K, Doenecke D, Gorlich D: The importin beta/importin 7 heterodimer is a functional nuclear import receptor for histone H1. Embo J 1999, 18:2411-2423.

42. Cassany A, Gerace L: Reconstitution of nuclear import in permeabilized cells. Methods Mol Biol 2009, 464:181-205.

43. Sugden B, Warren N: A promoter of Epstein-Barr virus that can function during latent infection can be transactivated by EBNA-1, a viral protein required for viral DNA replication during latent infection. J Virol 1989, 63:2644-2649. 
44. Kennedy G, Sugden B: EBNA-1, a bifunctional transcriptional activator. Mol Cell Biol 2003, 23:6901-6908.

45. Kitamura R, Sekimoto T, Ito S, Harada S, Yamagata H, Masai H, Yoneda Y, Yanagi K: Nuclear import of Epstein-Barr virus nuclear antigen 1 mediated by NPI-1 (Importin alpha5) is up- and down-regulated by phosphorylation of the nuclear localization signal for which Lys379 and Arg380 are essential. J Virol 2006, 80:1979-1991.

46. Nardozzi J, Wenta N, Yasuhara N, Vinkemeier U, Cingolani G: Molecular basis for the recognition of phosphorylated STAT1 by importin alpha5. J Mol Biol 2010, 402:83-100.

47. Kann M, Sodeik B, Vlachou A, Gerlich WH, Helenius A: Phosphorylationdependent binding of hepatitis $B$ virus core particles to the nuclear pore complex. I Cell Biol 1999, 145:45-55.

48. Kock J, Schlicht HJ: Analysis of the earliest steps of hepadnavirus replication: genome repair after infectious entry into hepatocytes does not depend on viral polymerase activity. J Virol 1993, 67:4867-4874.

49. Crowther RA, Kiselev NA, Bottcher B, Berriman JA, Borisova GP, Ose V, Pumpens P: Three-dimensional structure of hepatitis B virus core particles determined by electron cryomicroscopy. Cell 1994, 77:943-950.

50. Rabe B, Vlachou A, Pante N, Helenius A, Kann M: Nuclear import of hepatitis B virus capsids and release of the viral genome. Proc Natl Acad Sci USA 2003, 100:9849-9854.

51. Eckhardt SG, Milich DR, McLachlan A: Hepatitis B virus core antigen has two nuclear localization sequences in the arginine-rich carboxyl terminus. J Virol 1991, 65:575-582.

52. Hatton T, Zhou S, Standring DN: RNA- and DNA-binding activities in hepatitis B virus capsid protein: a model for their roles in viral replication. J Virol 1992, 66:5232-5241.

53. Liao W, Ou JH: Phosphorylation and nuclear localization of the hepatitis $B$ virus core protein: significance of serine in the three repeated SPRRR motifs. J Virol 1995, 69:1025-1029.

54. Zlotnick A, Cheng N, Stahl SJ, Conway JF, Steven AC, Wingfield PT: Localization of the $C$ terminus of the assembly domain of hepatitis $B$ virus capsid protein: implications for morphogenesis and organization of encapsidated RNA. Proc Natl Acad Sci USA 1997, 94:9556-9561.

55. Schmitz A, Schwarz A, Foss M, Zhou L, Rabe B, Hoellenriegel J, Stoeber M, Pante N, Kann M: Nucleoporin 153 arrests the nuclear import of hepatitis B virus capsids in the nuclear basket. PLoS Pathog 6:e1000741.

56. Seeger C, Mason WS: Hepatitis B virus biology. Microbiol Mol Biol Rev 2000, 64:51-68.

57. Xiao CY, Hubner S, Elliot RM, Caon A, Jans DA: A consensus CAMPdependent protein kinase (PK-A) site in place of the $\mathrm{CCN}$ motif casein kinase II site simian virus 40 large T-antigen confers PK-A-mediated regulation of nuclear import. J Biol Chem 1996, 271:6451-6457.

58. Hubner S, Xiao CY, Jans DA: The protein kinase CK2 site (Ser111/112) enhances recognition of the simian virus 40 large T-antigen nuclear localization sequence by importin. J Biol Chem 1997, 272:17191-17195.

59. Xiao CY, Hubner S, Jans DA: SV40 large tumor antigen nuclear import is regulated by the double-stranded DNA-dependent protein kinase site (serine 120) flanking the nuclear localization sequence. J Biol Chem 1997, 272:22191-22198.

60. Fontes MR, Teh T, Toth G, John A, Pavo I, Jans DA, Kobe B: Role of flanking sequences and phosphorylation in the recognition of the simian-virus40 large T-antigen nuclear localization sequences by importin-alpha. Biochem J 2003, 375:339-349.

61. Fontes MR, Teh T, Kobe B: Structural basis of recognition of monopartite and bipartite nuclear localization sequences by mammalian importinalpha. J Mol Biol 2000, 297:1183-1194

62. Vinkemeier U, Moarefi I, Darnell JE Jr, Kuriyan J: Structure of the aminoterminal protein interaction domain of STAT-4. Science 1998, 279:1048-1052.

63. Chen X, Vinkemeier U, Zhao Y, Jeruzalmi D, Darnell JE Jr, Kuriyan J: Crystal structure of a tyrosine phosphorylated STAT-1 dimer bound to DNA. Cell 1998, 93:827-839.

64. Mao X, Ren Z, Parker GN, Sondermann H, Pastorello MA, Wang W, McMurray JS, Demeler B, Darnell JE Jr, Chen X: Structural bases of unphosphorylated STAT1 association and receptor binding. Mol Cell 2005, 17:761-771.

65. Becker S, Corthals GL, Aebersold R, Groner B, Muller CW: Expression of a tyrosine phosphorylated, DNA binding Stat3beta dimer in bacteria. FEBS Lett 1998, 441:141-147.
66. Wojciak JM, Martinez-Yamout MA, Dyson HJ, Wright PE: Structural basis for recruitment of $\mathrm{CBP} / \mathrm{p} 300$ coactivators by STAT1 and STAT2 transactivation domains. EMBO J 2009, 28:948-958.

67. Darnell JE Jr: STATs and gene regulation. Science 1997, 277:1630-1635.

68. Shuai K, Stark GR, Kerr IM, Darnell JE Jr: A single phosphotyrosine residue of Stat91 required for gene activation by interferon-gamma. Science 1993, 261:1744-1746

69. Wenta N, Strauss H, Meyer S, Vinkemeier U: Tyrosine phosphorylation regulates the partitioning of STAT1 between different dimer conformations. Proc Natl Acad Sci USA 2008, 105:9238-9243.

70. Meyer T, Begitt A, Lodige I, van Rossum M, Vinkemeier U: Constitutive and IFN-gamma-induced nuclear import of STAT1 proceed through independent pathways. Embo $\mathrm{J}$ 2002, 21:344-354.

71. Fagerlund R, Melen K, Kinnunen L, Julkunen I: Arginine/lysine-rich nuclear localization signals mediate interactions between dimeric STATs and importin alpha 5. J Biol Chem 2002, 277:30072-30078.

72. Melen K, Fagerlund R, Franke J, Kohler M, Kinnunen L, Julkunen I: Importin alpha nuclear localization signal binding sites for STAT1, STAT2, and influenza A virus nucleoprotein. J Biol Chem 2003, 278:28193-28200.

73. McBride KM, Banninger G, McDonald C, Reich NC: Regulated nuclear import of the STAT1 transcription factor by direct binding of importinalpha. Embo J 2002, 21:1754-1763.

74. Sekimoto T, Imamoto N, Nakajima K, Hirano T, Yoneda Y: Extracellular signal-dependent nuclear import of Stat1 is mediated by nuclear poretargeting complex formation with NPI-1, but not Rch1. Embo J 1997, 16:7067-7077.

75. Li X, Leung S, Qureshi S, Darnell JE Jr, Stark GR: Formation of STAT1-STAT2 heterodimers and their role in the activation of IRF-1 gene transcription by interferon-alpha. J Biol Chem 1996, 271:5790-5794.

76. Kato Y, Tapping RI, Huang S, Watson MH, Ulevitch RJ, Lee JD: Bmk1/Erk5 is required for cell proliferation induced by epidermal growth factor. Nature 1998, 395:713-716.

77. Meloche S, Pouyssegur J: The ERK $1 / 2$ mitogen-activated protein kinase pathway as a master regulator of the G1- to S-phase transition. Oncogene 2007, 26:3227-3239.

78. Kato Y, Kravchenko W, Tapping Rl, Han J, Ulevitch RJ, Lee JD: BMK1/ERK5 regulates serum-induced early gene expression through transcription factor MEF2C. Embo J 1997, 16:7054-7066.

79. Kamakura S, Moriguchi T, Nishida E: Activation of the protein kinase ERK5/ BMK1 by receptor tyrosine kinases. Identification and characterization of a signaling pathway to the nucleus. J Biol Chem 1999, 274:26563-26571.

80. Morimoto H, Kondoh K, Nishimoto S, Terasawa K, Nishida E: Activation of a C-terminal transcriptional activation domain of ERK5 by autophosphorylation. J Biol Chem 2007, 282:35449-35456.

81. Raviv Z, Kalie E, Seger R: MEK5 and ERK5 are localized in the nuclei of resting as well as stimulated cells, while MEKK2 translocates from the cytosol to the nucleus upon stimulation. J Cell Sci 2004, 117:1773-1784.

82. Buschbeck $M, U$ Ulrich $A$ : The unique $C$-terminal tail of the mitogenactivated protein kinase ERK5 regulates its activation and nuclear shuttling. J Biol Chem 2005, 280:2659-2667.

83. Kondoh K, Terasawa K, Morimoto H, Nishida E: Regulation of nuclear translocation of extracellular signal-regulated kinase 5 by active nuclear import and export mechanisms. Mol Cell Biol 2006, 26:1679-1690.

84. Chao TH, Hayashi M, Tapping Rl, Kato Y, Lee JD: MEKK3 directly regulates MEK5 activity as part of the big mitogen-activated protein kinase 1 (BMK1) signaling pathway. J Biol Chem 1999, 274:36035-36038.

85. McCracken SR, Ramsay A, Heer R, Mathers ME, Jenkins BL, Edwards J, Robson CN, Marquez R, Cohen P, Leung HY: Aberrant expression of extracellular signal-regulated kinase 5 in human prostate cancer. Oncogene 2008, 27:2978-2988.

86. Nicol RL, Frey N, Pearson G, Cobb M, Richardson J, Olson EN: Activated MEK5 induces serial assembly of sarcomeres and eccentric cardiac hypertrophy. EMBO J 2001, 20:2757-2767.

87. Pi X, Garin G, Xie L, Zheng Q, Wei H, Abe J, Yan C, Berk BC: BMK1/ERK5 is a novel regulator of angiogenesis by destabilizing hypoxia inducible factor 1alpha. Circ Res 2005, 96:1145-1151.

88. Mebratu Y, Tesfaigzi Y: How ERK1/2 activation controls cell proliferation and cell death: Is subcellular localization the answer? Cell Cycle 2009, 8:1168-1175. 
89. Yu W, Fantl WJ, Harrowe G, Williams LT: Regulation of the MAP kinase pathway by mammalian Ksr through direct interaction with MEK and ERK. Curr Biol 1998, 8:56-64.

90. Tanoue T, Adachi M, Moriguchi T, Nishida E: A conserved docking motif in MAP kinases common to substrates, activators and regulators. Nat Cell Biol 2000, 2:110-116.

91. Chuderland D, Seger R: Protein-protein interactions in the regulation of the extracellular signal-regulated kinase. Mol Biotechnol 2005, 29:57-74.

92. Adachi M, Fukuda M, Nishida E: Two co-existing mechanisms for nuclear import of MAP kinase: passive diffusion of a monomer and active transport of a dimer. Embo J 1999, 18:5347-5358.

93. Khokhlatchev AV, Canagarajah B, Wilsbacher J, Robinson M, Atkinson M, Goldsmith E, Cobb MH: Phosphorylation of the MAP kinase ERK2 promotes its homodimerization and nuclear translocation. Cell 1998, 93:605-615.

94. Robinson FL, Whitehurst AW, Raman M, Cobb MH: Identification of novel point mutations in ERK2 that selectively disrupt binding to MEK1. J Biol Chem 2002, 277:14844-14852.

95. Chuderland D, Konson A, Seger R: Identification and characterization of a general nuclear translocation signal in signaling proteins. Mol Cell 2008, 31:850-861.

96. Hill CS: Nucleocytoplasmic shuttling of Smad proteins. Cell Res 2009, 19:36-46.

97. Pei JJ, Braak H, An WL, Winblad B, Cowburn RF, Iqbal K, Grundke-lqbal I: Up-regulation of mitogen-activated protein kinases ERK1/2 and MEK1/2 is associated with the progression of neurofibrillary degeneration in Alzheimer's disease. Brain Res Mol Brain Res 2002, 109:45-55.

98. Lin S, Fu XD: SR proteins and related factors in alternative splicing. $A d v$ Exp Med Biol 2007, 623:107-122.

99. Caceres JF, Screaton GR, Krainer AR: A specific subset of SR proteins shuttles continuously between the nucleus and the cytoplasm. Genes Dev 1998, 12:55-66.

100. Li X, Manley JL: New talents for an old acquaintance: the SR protein splicing factor ASF/SF2 functions in the maintenance of genome stability. Cell Cycle 2005, 4:1706-1708.

101. Li X, Manley JL: Inactivation of the SR protein splicing factor ASF/SF2 results in genomic instability. Cell 2005, 122:365-378.

102. Hedley ML, Amrein H, Maniatis T: An amino acid sequence motif sufficient for subnuclear localization of an arginine/serine-rich splicing factor. Proc Natl Acad Sci USA 1995, 92:11524-11528.

103. Lai MC, Lin RI, Tarn WY: Transportin-SR2 mediates nuclear import of phosphorylated SR proteins. Proc Natl Acad Sci USA 2001, 98:10154-10159.

104. Lai MC, Lin RI, Huang SY, Tsai CW, Tarn WY: A human importin-beta family protein, transportin-SR2, interacts with the phosphorylated RS domain of SR proteins. J Biol Chem 2000, 275:7950-7957.

105. Kehlenbach RH, Gerace L: Phosphorylation of the nuclear transport machinery down-regulates nuclear protein import in vitro. J Biol Chem 2000, 275:17848-17856

106. Porter FW, Bochkov YA, Albee AJ, Wiese C, Palmenberg AC: A picornavirus protein interacts with Ran-GTPase and disrupts nucleocytoplasmic transport. Proc Natl Acad Sci USA 2006, 103:12417-12422.

107. Porter FW, Palmenberg AC: Leader-induced phosphorylation of nucleoporins correlates with nuclear trafficking inhibition by cardioviruses. J Virol 2009, 83:1941-1951.

108. Chen LF, Greene WC: Shaping the nuclear action of NF-kappaB. Nat ReV Mol Cell Biol 2004, 5:392-401.

109. McCaffrey PG, Luo C, Kerppola TK, Jain J, Badalian TM, Ho AM, Burgeon E, Lane WS, Lambert JN, Curran T, et al: Isolation of the cyclosporin-sensitive T cell transcription factor NFATp. Science 1993, 262:750-754.

110. Jain J, McCaffrey PG, Miner Z, Kerppola TK, Lambert JN, Verdine GL, Curran T, Rao A: The T-cell transcription factor NFATp is a substrate for calcineurin and interacts with Fos and Jun. Nature 1993, 365:352-355.

111. Ho SN, Thomas DJ, Timmerman LA, Li X, Francke U, Crabtree GR: NFATc3, a lymphoid-specific NFATc family member that is calcium-regulated and exhibits distinct DNA binding specificity. J Biol Chem 1995, 270:19898-19907.

112. Ortega-Perez I, Cano E, Were F, Villar M, Vazquez J, Redondo JM: c-Jun Nterminal kinase (JNK) positively regulates NFATc2 transactivation through phosphorylation within the $\mathrm{N}$-terminal regulatory domain. J Biol Chem 2005, 280:20867-20878.
113. Kehlenbach RH, Dickmanns A, Gerace L: Nucleocytoplasmic shuttling factors including Ran and CRM1 mediate nuclear export of NFAT In vitro. J Cell Biol 1998, 141:863-874.

114. Belfield JL, Whittaker C, Cader MZ, Chawla S: Differential effects of Ca2+ and CAMP on transcription mediated by MEF2 D and CAMP-response element-binding protein in hippocampal neurons. J Biol Chem 2006, 281:27724-27732.

115. Loh C, Shaw KT, Carew J, Viola JP, Luo C, Perrino BA, Rao A: Calcineurin binds the transcription factor NFAT1 and reversibly regulates its activity. J Biol Chem 1996, 271:10884-10891.

116. Graef IA, Wang F, Charron F, Chen L, Neilson J, Tessier-Lavigne M, Crabtree GR: Neurotrophins and netrins require calcineurin/NFAT signaling to stimulate outgrowth of embryonic axons. Cell 2003, 113:657-670.

117. Mansuy IM: Calcineurin in memory and bidirectional plasticity. Biochem Biophys Res Commun 2003, 311:1195-1208.

118. Kronenberg HM, Karaplis AC, Lanske B: Role of parathyroid hormonerelated protein in skeletal development. Ann N Y Acad Sci 1996, 785:119-123.

119. Philbrick WM, Wysolmerski JJ, Galbraith S, Holt E, Orloff JJ, Yang KH, Vasavada RC, Weir EC, Broadus AE, Stewart AF: Defining the roles of parathyroid hormone-related protein in normal physiology. Physiol Rev 1996, 76:127-173.

120. Clemens TL, Cormier S, Eichinger A, Endlich K, Fiaschi-Taesch N, Fischer E, Friedman PA, Karaplis AC, Massfelder T, Rossert J, et al: Parathyroid hormone-related protein and its receptors: nuclear functions and roles in the renal and cardiovascular systems, the placental trophoblasts and the pancreatic islets. Br J Pharmacol 2001, 134:1113-1136.

121. Lam MH, Thomas RJ, Martin TJ, Gillespie MT, Jans DA: Nuclear and nucleolar localization of parathyroid hormone-related protein. Immunol Cell Biol 2000, 78:395-402

122. Henderson JE, Amizuka N, Warshawsky H, Biasotto D, Lanske BM, Goltzman D, Karaplis AC: Nucleolar localization of parathyroid hormonerelated peptide enhances survival of chondrocytes under conditions that promote apoptotic cell death. Mol Cell Biol 1995, 15:4064-4075.

123. Lam MH, Briggs $\sqcup$, Hu W, Martin TJ, Gillespie MT, Jans DA: Importin beta recognizes parathyroid hormone-related protein with high affinity and mediates its nuclear import in the absence of importin alpha. J Biol Chem 1999, 274:7391-7398.

124. Lam MH, House CM, Tiganis T, Mitchelhill Kl, Sarcevic B, Cures A, Ramsay R, Kemp BE, Martin TJ, Gillespie MT: Phosphorylation at the cyclindependent kinases site (Thr85) of parathyroid hormone-related protein negatively regulates its nuclear localization. J Biol Chem 1999, 274:18559-18566.

125. Koerner C, Guan T, Gerace L, Cingolani G: Synergy of silent and hot spot mutations in importin beta reveals a dynamic mechanism for recognition of a nuclear localization signal. J Biol Chem 2003, 278:16216-16221.

126. Ruis H, Schuller C: Stress signaling in yeast. Bioessays 1995, 17:959-965.

127. Gasch AP, Spellman PT, Kao CM, Carmel-Harel O, Eisen MB, Storz G, Botstein D, Brown PO: Genomic expression programs in the response of yeast cells to environmental changes. Mol Biol Cell 2000, 11:4241-4257.

128. Gorner W, Durchschlag E, Martinez-Pastor MT, Estruch F, Ammerer G, Hamilton B, Ruis $\mathrm{H}$, Schuller $\mathrm{C}$ : Nuclear localization of the $\mathrm{C} 2 \mathrm{H} 2$ zinc finger protein Msn2p is regulated by stress and protein kinase $A$ activity. Genes Dev 1998, 12:586-597.

129. Gorner W, Durchschlag E, Wolf J, Brown EL, Ammerer G, Ruis H, Schuller C: Acute glucose starvation activates the nuclear localization signal of a stress-specific yeast transcription factor. Embo J 2002, 21:135-144.

130. Oshima Y: The phosphatase system in Saccharomyces cerevisiae. Genes Genet Syst 1997, 72:323-334.

131. Komeili A, O'Shea EK: Roles of phosphorylation sites in regulating activity of the transcription factor Pho4. Science 1999, 284:977-980.

132. O'Neill EM, Kaffman A, Jolly ER, O'Shea EK: Regulation of PHO4 nuclear localization by the PHO80-PHO85 cyclin-CDK complex. Science 1996, 271:209-212

133. Kaffman A, Rank NM, O'Shea EK: Phosphorylation regulates association of the transcription factor Pho4 with its import receptor Pse1/Kap121. Genes Dev 1998, 12:2673-2683.

134. Queralt E, Igual JC: Cell cycle activation of the Swi6p transcription factor is linked to nucleocytoplasmic shuttling. Mol Cell Biol 2003, 23:3126-3140. 
135. Sidorova JM, Mikesell GE, Breeden LL: Cell cycle-regulated phosphorylation of Swi6 controls its nuclear localization. Mol Biol Cell 1995, 6:1641-1658.

136. Harreman MT, Kline TM, Milford HG, Harben MB, Hodel AE, Corbett AH: Regulation of nuclear import by phosphorylation adjacent to nuclear localization signals. J Biol Chem 2004, 279:20613-20621.

137. Alexander WS: Suppressors of cytokine signalling (SOCS) in the immune system. Nat Rev Immunol 2002, 2:410-416.

138. Rogers RS, Horvath CM, Matunis MJ: SUMO modification of STAT1 and its role in PIAS-mediated inhibition of gene activation. J Biol Chem 2003, 278:30091-30097.

139. Lorenzen JA, Dadabay CY, Fischer EH: $\mathrm{COOH}$-terminal sequence motifs target the T cell protein tyrosine phosphatase to the ER and nucleus. $J$ Cell Biol 1995, 131:631-643.

140. Tillmann U, Wagner J, Boerboom D, Westphal H, Tremblay ML: Nuclear localization and cell cycle regulation of a murine protein tyrosine phosphatase. Mol Cell Biol 1994, 14:3030-3040.

141. ten Hoeve J, de Jesus Ibarra-Sanchez M, Fu Y, Zhu W, Tremblay M, David M, Shuai K: Identification of a nuclear Stat1 protein tyrosine phosphatase. Mol Cell Biol 2002, 22:5662-5668.

142. Begitt A, Meyer T, van Rossum M, Vinkemeier U: Nucleocytoplasmic translocation of Stat 1 is regulated by a leucine-rich export signal in the coiled-coil domain. Proc Natl Acad Sci USA 2000, 97:10418-10423.

143. Hof P, Pluskey S, Dhe-Paganon S, Eck MJ, Shoelson SE: Crystal structure of the tyrosine phosphatase SHP-2. Cell 1998, 92:441-450.

144. Neel BG, Gu H, Pao L: The 'Shp'ing news: SH2 domain-containing tyrosine phosphatases in cell signaling. Trends Biochem Sci 2003, 28:284-293.

145. Klingmuller U, Lorenz U, Cantley LC, Neel BG, Lodish HF: Specific recruitment of SH-PTP1 to the erythropoietin receptor causes inactivation of JAK2 and termination of proliferative signals. Cell 1995, 80:729-738.

146. Wu TR, Hong YK, Wang XD, Ling MY, Dragoi AM, Chung AS, Campbell AG, Han ZY, Feng GS, Chin YE: SHP-2 is a dual-specificity phosphatase involved in Stat 1 dephosphorylation at both tyrosine and serine residues in nuclei. J Biol Chem 2002, 277:47572-47580.

147. Pogo BG, Melana SM, Blaho J: Poxvirus infection and apoptosis. Int Rev Immunol 2004, 23:61-74.

148. Liu K, Lemon B, Traktman P: The dual-specificity phosphatase encoded by vaccinia virus, $\mathrm{VH} 1$, is essential for viral transcription in vivo and in vitro. J Virol 1995, 69:7823-7834.

149. Derrien M, Punjabi A, Khanna M, Grubisha O, Traktman P: Tyrosine phosphorylation of A17 during vaccinia virus infection: involvement of the H1 phosphatase and the F10 kinase. J Virol 1999, 73:7287-7296.

150. Mercer J, Traktman P: Investigation of structural and functional motifs within the vaccinia virus A14 phosphoprotein, an essential component of the virion membrane. J Virol 2003, 77:8857-8871.

151. Najarro $P$, Traktman $P$, Lewis JA: Vaccinia virus blocks gamma interferon signal transduction: viral VH1 phosphatase reverses Stat1 activation. $J$ Virol 2001, 75:3185-3196.

152. Koksal AC, Nardozzi JD, Cingolani G: Dimeric quaternary structure of the prototypical dual specificity phosphatase VH1. J Biol Chem 2009, 284:10129-10137.

153. Marg A, Shan Y, Meyer T, Meissner T, Brandenburg M, Vinkemeier U: Nucleocytoplasmic shuttling by nucleoporins Nup153 and Nup214 and CRM1-dependent nuclear export control the subcellular distribution of latent Stat1. J Cell Biol 2004, 165:823-833.

154. Best SM, Morris KL, Shannon JG, Robertson SJ, Mitzel DN, Park GS, Boer E, Wolfinbarger JB, Bloom ME: Inhibition of interferon-stimulated JAK-STAT signaling by a tick-borne flavivirus and identification of NS5 as an interferon antagonist. J Virol 2005, 79:12828-12839.

155. Lin RJ, Chang BL, Yu HP, Liao CL, Lin YL: Blocking of interferon-induced Jak-Stat signaling by Japanese encephalitis virus NS5 through a protein tyrosine phosphatase-mediated mechanism. J Virol 2006, 80:5908-5918

156. Mazzon M, Jones M, Davidson A, Chain B, Jacobs M: Dengue virus NS5 inhibits interferon-alpha signaling by blocking signal transducer and activator of transcription 2 phosphorylation. J Infect Dis 2009, 200:1261-1270

157. Krebs EHFaEG: Conversion of Phosphorylase $b$ to Phosphorylase $a$ in Muscle Extracts. Journal of Biological Chemistry 1955, 216:121-132.
158. Jans DA, Thomas RJ, Gillespie MT: Parathyroid hormone-related protein (PTHrP): a nucleocytoplasmic shuttling protein with distinct paracrine and intracrine roles. Vitam Horm 2003, 66:345-384.

159. Khodarev NN, Minn AJ, Efimova EV, Darga TE, Labay E, Beckett M, Mauceri HJ, Roizman B, Weichselbaum RR: Signal transducer and activator of transcription 1 regulates both cytotoxic and prosurvival functions in tumor cells. Cancer Res 2007, 67:9214-9220.

160. Khodarev NN, Beckett M, Labay E, Darga T, Roizman B, Weichselbaum RR: STAT1 is overexpressed in tumors selected for radioresistance and confers protection from radiation in transduced sensitive cells. Proc Natl Acad Sci USA 2004, 101:1714-1719.

161. Meng Y, Mauceri HJ, Khodarev NN, Darga TE, Pitroda SP, Beckett MA, Kufe DW, Weichselbaum RR: Ad.Egr-TNF and local ionizing radiation suppress metastases by interferon-beta-dependent activation of antigen-specific CD8+ T cells. Mol Ther 2010, 18:912-920.

162. Pitroda SP, Wakim BT, Sood RF, Beveridge MG, Beckett MA MacDermed DM, Weichselbaum RR, Khodarev NN: STAT1-dependent expression of energy metabolic pathways links tumour growth and radioresistance to the Warburg effect. BMC Med 2009, 7:68.

163. Khodarev NN, Roach P, Pitroda SP, Golden DW, Bhayani M, Shao MY, Darga TE, Beveridge MG, Sood RF, Sutton HG, et al: STAT1 pathway mediates amplification of metastatic potential and resistance to therapy. PLoS One 2009, 4:e5821.

164. Thompson JD, Higgins DG, Gibson TJ: CLUSTAL W: improving the sensitivity of progressive multiple sequence alignment through sequence weighting, position-specific gap penalties and weight matrix choice. Nucleic Acids Res 1994, 22:4673-4680.

doi:10.1186/1478-811X-8-32

Cite this article as: Nardozzi et al: Phosphorylation meets nuclear import: a review. Cell Communication and Signaling 2010 8:32.

\section{Submit your next manuscript to BioMed Central and take full advantage of:}

- Convenient online submission

- Thorough peer review

- No space constraints or color figure charges

- Immediate publication on acceptance

- Inclusion in PubMed, CAS, Scopus and Google Scholar

- Research which is freely available for redistribution

Submit your manuscript at www.biomedcentral.com/submit
Ciomed Central 